\title{
PENGARUH TEMPERATUR KARBONISASI TERHADAP MIKROSTRUKTUR DAN PEMBENTUKAN KRISTAL PADA BIOKARBON ECENG GONDOK SEBAGAI BAHAN DASAR ABSORBER GELOMBANG ELEKTROMAGNETIK RADAR
}

\author{
Muzakhim Imammuddin ${ }^{1 *}$, Sudjito Soeparman², Wahyono Suprapto², \\ Achmad As'ad Sonief ${ }^{2}$ \\ 'Jurusan Teknik Elektro, Program Studi Teknik Telekomunikasi, Politeknik Negeri Malang \\ 2Jurusan Teknik Mesin, Fakutas Teknik, Universitas Brawijaya Malang \\ *Email:azam@polinema.ac.id
}

\begin{abstract}
Radar Absorbing Materials (RAM) or radar absorbing materials of radar electromagnetic waves are materials used to reduce or eliminate radiation of radar electromagnetic waves in order to avoid reflection of waves. At this time the development of RAM research leads to materials derived from nature. Some materials derived from nature that has been used as RAM such as rice husk, bamboo, coconut shell, coconut husk, wood fiber and wood flour. In this study, eichornia crassipe is made into biocarbon or activated carbon for use as a base material for RAM. Carbonization is one way to transform water hyacinth into biocarbon or activated carbon. The method used in this research is Experimental Research. The independent variables of this research are carbonization temperature starting from temperature $500^{\circ} \mathrm{C}, 600^{\circ} \mathrm{C}, 700^{\circ} \mathrm{C}, 800^{\circ} \mathrm{C}$, $900^{\circ} \mathrm{C}$ and $1000^{\circ} \mathrm{C}$. The results showed that the higher the carbonization temperature, the more open pores will be with $2 \mu \mathrm{m}$ diameter at $1000^{\circ} \mathrm{C}$, and the higher the carbonization temperature than the percentage of carbon crystal formed higher with the value of $14 \%$ at temperatures $900^{\circ} \mathrm{C}$ and $1000^{\circ} \mathrm{C}$. The biocarbon structure of eichornia crassipe is crystalline and amorphous making it suitable for use as RAM material.
\end{abstract}

Keywords: Biocarbon, Eichornia crassipe, Radar Absorbing Material, Temperature

\section{PENDAHULUAN}

Pada saat ini perkembangan peralatan perang sudah semakin maju, seperti pembuatan pesawat tempur, kapal perang, kendaraan tempur atau peralatan perang yang lain tidak dapat terdeteksi oleh radar. Dimana dalam sistem radar menggunakan metode membaca gelombang pantul dari pesawat tempur yang terkena gelombang elektromagnetik yang dipancarkan. Dan agar suatu peralatan perang tidak dapat terdeteksi oleh radar maka peralatan perang itu dilapisi bahan yang dapat menyerap radiasi gelombang elektromagnetik yang dipancarkan radar. Bahan itu disebut Radar Absorbing Materials (RAM) atau material penyerap radar, RAM dapat dibuat dari berbagai jenis material seperti: cat konduktif atau karet yang diisi ferit atau partikel karbon aktif yang dikembangkan untuk pesawat militer siluman, sementara busa konduktif dan atau topologi multilayer umumnya digunakan sebagai pelapis untuk semua pagar atau dinding dimana pantulan gelombang harus diminimalisir[1].
Beberapa bahan yang berasal dari alam yang telah digunakan sebagai bahan dasar RAM seperti: sekam padi[2], bamboo[3], sabut kelapa[4], batok kelapa[5], dan tepung kayu, sabut kayu dan buangan selulosa fiber[6]. Oleh karena itu, pemanfaatan sampah alam sangat perlu untuk diteliti dan dikembangkan menjadi material yang berdayaguna tinggi. Disamping sampah alam, ada juga tanaman yang bersifat gulma atau menganggu seperti eceng gondok atau Eichornia crassipe. Eceng gondok sangat mudah tumbuh di perairan sungai, rawa dan danau.

Eceng gondok memiliki tiga komponen utama yaitu selullosa, hemiselullosa dan lignin. Dalam batang tumbuhan eceng gondok memiliki kandungan selulosa $50 \%$, Lignin $30 \%$, sisanya adalah hemiselullosa dan zat-zat yang lain dan memiliki kandungan kimia yang tergantung dari unsur hara tempat eceng gondok tumbuh[7]. Berdasarkan hal terserbut diatas maka eceng gondok merupakan salah satu material alam yang cocok untuk digunakan sebagai bahan dasar dari material karbon yang 
digunakan untuk penyerap radiasi gelombang $\mathrm{nm}$, dan pori makro (macropores) dengan elektromagnetik radar. Dengan mengingat ukuran $\geq 50 \mathrm{~nm}$.

bahwa teknologi pertahanan negara Indonesia perlu untuk dikembangkan. Dan salah satu teknologi pertahanan adalah material anti radar. Sehingga nantinya akan didapatkan bahan baku material anti radar yang murah harganya dan mudah didapatkan.

Karbon aktif merupakan karbon yang mempunyai rumus kimia $C$ dan berbentuk amorf, yang dapat dihasilkan dari bahan-bahan yang mengandung karbon atau dari arang yang diperlakukan dengan cara khusus untuk mendapatkan permukaan yang lebih luas. Luas permukaan karbon aktif berkisar antara 300 $2000 \mathrm{~m}^{2} / \mathrm{gram}$ dan ini berhubungan dengan struktur pori internal yang menyebabkan karbon aktif mempunyai sifat sebagai adsorben. Karbon aktif dapat mengadsorbsi gas dan senyawa-senyawa kimia tertentu atau sifat adsorbsinya selektif, tergantung pada besar atau volume pori-pori dan luas permukaan. Daya serap arang aktif sangat besar, yaitu dengan rentang $25-1000 \%$ terhadap berat karbon aktif[8]. Gambar 1 menunjukkan struktur pori dari karbon aktif. Yang terdiri dari tiga jenis pori yang bergantung dari ukuran dari pori yaitu: pori mikro (micropores) dengan ukuran $\leq 2 \mathrm{~nm}$, pori meso (mesopores) dengan ukuran $2-50$

Struktur karbon aktif menyerupai struktur grafit. Grafit mempunyai susunan seperti pelatpelat yang sebagian besar terbentuk dari atom karbon yang berbentuk heksagonal. Jarak antara atom karbon dalam masing-masing lapisan 1,42 A. Pada grafit, jarak antara pelatpelat lebih dekat dan terikat lebih teratur daripada struktur karbon aktif. Gambar 2a struktur grafit dan gambar $2 \mathrm{~b}$ berstruktur umum karbon aktif[9].

Dalam pembuatan karbon aktif terdiri dari tiga tahap yaitu[10]:

Dehidrasi: proses penghilangan air. Bahan baku dipanaskan sampai temperatur $170^{\circ} \mathrm{C}$.

Karbonisasi: pemecahan bahan-bahan organik menjadi karbon. Karbonasi dilakukan pada suhu $400-900^{\circ} \mathrm{C}$. Temperatur diatas $170^{\circ} \mathrm{C}$ akan menghasilkan $\mathrm{CO}, \mathrm{CO} 2$ dan asam asetat. Pada temperatur $275^{\circ} \mathrm{C}$, dekomposisi menghasilkan tar, metanol dan hasil sampingan lainnya. Pembentukan karbon terjadi pada temperatur $400-600 \stackrel{\circ}{\mathrm{C}}$.

Proses pirolisis atau karbonisasi dapat diwakili oleh reaksi umum sebagai berikut[12]:

$$
\begin{aligned}
\mathrm{C}_{n} \mathrm{H}_{m} \mathrm{O}_{p} & \rightarrow \sum_{\text {liquid }} \mathrm{C}_{x} \mathrm{H}_{y} \mathrm{O}_{z}+\sum_{\text {gas }} \mathrm{C}_{\mathrm{a}} \mathrm{H}_{\mathrm{y}} \mathrm{O}_{z} \\
& +\mathrm{H}_{2} \mathrm{O}+\mathrm{C}(\text { char })
\end{aligned}
$$

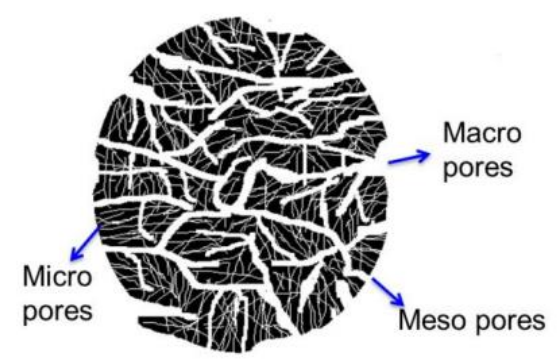

Gambar 1. Stuktur pori dari karbon aktif[11]

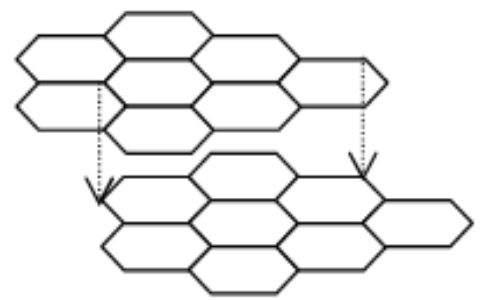

a.

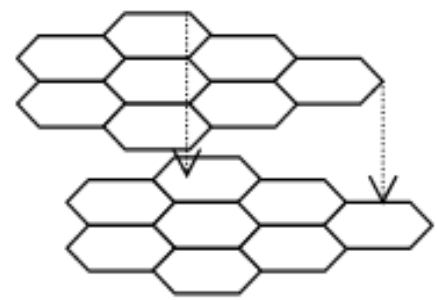

b.

Gambar 2. a Struktur Grafit dan b Struktur Karbon Aktif[9] 
Dimana $\mathrm{C}_{\mathrm{n}} \mathrm{H}_{\mathrm{m}} \mathrm{O}_{\mathrm{p}}=$ biomassa

Dengan asumsi selulosa merupakan biomassa maka untuk mendapatkan karbon mempunyai persamaan stoikiometri sebagai berikut[12]:

$$
\begin{aligned}
\mathrm{C}_{6} \mathrm{H}_{10} \mathrm{O}_{5} \rightarrow & 3,74 \mathrm{C}+2,65 \mathrm{H}_{2} \mathrm{O}+1,17 \mathrm{CO}_{2} \\
& +1,08 \mathrm{CH}_{4}
\end{aligned}
$$

Aktivasi: Dekomposisi tar dan perluasan pori-pori. Proses aktivasi terjadi pada temperatur $500-1000^{\circ} \mathrm{C}$. Proses ini dapat dilakukan dengan uap atau $\mathrm{CO}_{2}$ sebagai aktivator. Karbon dihasilkan dari pembakaran tidak sempurna. Secara umum reaksinya dapat ditulis sebagai berikut:

$$
\begin{array}{r}
\mathrm{C}_{6} \mathrm{H}_{10} \mathrm{O}_{5}+\mathrm{O}_{2}(\mathrm{~g}) \rightarrow 4 \mathrm{C}(\mathrm{s})+2 \mathrm{CO}(\mathrm{g}) \\
+5 \mathrm{H}_{2} \mathrm{O}(\mathrm{g})
\end{array}
$$

Pembakaran tidak sempurna tidak terjadi bila hidrokarbon berlebih atau kekurangan oksigen pada penukaran sempurna hanya dihasilkan $\mathrm{CO}_{2}$ dan $\mathrm{H}_{2} \mathrm{O}$, sedangkan pada pembakaran tidak sempurna selain dihasilkan $\mathrm{CO}_{2}$ dan $\mathrm{H}_{2} \mathrm{O}$ juga dihasilkan $\mathrm{CO}$ dan $\mathrm{C}$ [8]. Tujuan proses aktivasi karbon yaitu untuk memperbesar luas permukaan arang dengan membuka pori-pori yang tertutup. Semakin tinggi temperatur aktivasi maka semakin banyak pori-pori terbuka dan pori bertambah luas[13-16]. Dengan bertambahnya pori yang terbuka maka nilai konduktivitas akan bertambah[17].

\section{METODOLOGI PENELITIAN}

\section{Preparasi Eceng Gondok}

Preparasi yang dilakukan adalah pemotongan pencucian dan pengeringan eceng gondok. Eceng gondok yang digunakan adalah bagian batang dan daunnya. Eceng gondok yang digunakan berasal dari daerah sumber air Wendit Malang. Proses pengeringan dilakukan menggunakan oven dengan temperatur $70^{\circ} \mathrm{C}$ selama 4 hari. Kemudian eceng gondok dijadikan serbuk dengan ukuran 80 mesh. Hal ini dilakukan agar distibusi panas saat proses karbonisasi merata.

\section{Karbonisasi}

Serbuk eceng gondok diletakkan di dalam tungku besi yang tertutup yang dilengkapi dengan pengaman tekanan, kemudian dimasukkan ke horisontal furnace. Proses karbonisasi dilakukan dalam keadaan minim oksigen. Serbuk eceng gondok dipanaskan dari temperatur ruangan ke temperatur $500^{\circ} \mathrm{C}$, $600^{\circ} \mathrm{C}, 700^{\circ} \mathrm{C}, 800^{\circ} \mathrm{C}, 900^{\circ} \mathrm{C}$ dan $1000^{\circ} \mathrm{C}$ dengan dengan waktu penahanan selama 1 jam, kemudian didinginkan secara alami sampai mencapai temperatur ruangan.

\section{Karakterisasi Biokarbon Eceng Gondok}

Pengujian mikrostruktur biokarbon eceng gondok dilakukan dengan menggunakan scanning electron microscope (SEM) di laboraturium Energi dan Lingkungan LPPM-ITS dan pengujian karakterisasi kristal biokarbon eceng gondok dilakukan dengan menggunakan difraksi sinar - $\mathrm{X}(X R D)$ di laboraturium Mineral dan Material Maju FMIPA Universitas Negeri Malang.

\section{HASIL DAN PEMBAHASAN \\ Hasil Pengujian SEM}

Hasil SEM biokarbon eceng gondok dengan pembesaran 2000x dalam Gambar 3 menunjukkan semakin tinggi temperatur karbonisasi maka semakin banyak pori-pori dari biokarbon eceng gondok yang terbuka. Pada temperatur $500^{\circ} \mathrm{C}$ (Gambar 3.a) hanya sedikit pori-pori biokarbon eceng gondok yang terbuka, pada temperatur $600^{\circ} \mathrm{C}$ (Gambar 3.b) bertambah banyak pori-pori yang terbuka dengan diameter pori sekitar $10 \mu \mathrm{m}$, pada temperatur $700^{\circ} \mathrm{C}$ (Gambar 3.c) mulai terlihat bentuk dari pori-pori biokarbon eceng gondok yang berbentuk karang atau sponge dengan bentuk yang asimetris. Semakin bertambahnya temperatur karbonisasi maka diamater pori akan semakin kecil hingga pada tempeartur $1000^{\circ} \mathrm{C}$ biokarbon eceng gondok memiliki diameter pori-pori sekitar $2 \mu \mathrm{m}$. Dengan adanya pori-pori ini, maka biokarbon eceng gondok sangat cocok digunakan sebagai bahan dasar RAM karena ketika ada gelombang elektromagnetik radar yang menabrak biokarbon eceng gondok maka gelombang itu tidak dipantulkan, tetapi akan dibelokkan masuk ke dalam pori-pori, kemudian akan di pantulkan ke dalam pori-pori yang lebih dalam lagi, sehingga gelombang akan rusak dan kehabisan energi. Sehingga biokarbon eceng gondok yang berpori-pori luas dapat meningkatkan penyerapan radiasi gelombang 
elektromagnetik dengan refleksi permukaan yang rendah dan disipasi panas juga lebih baik dari energi yang diserap karena adanya fraksi volume udara yang tinggi, atau mekanisme penyerapan radiasi refreksi berkelipatan (multiple reflection)[18]. Gambar 4 merupakan ilustrasi dari gelombang elektromagnetik yang terjebak di dalam pori-pori biokarbon eceng gondok. Disamping itu, Destyorini dkk[17] menyatakan bahwa bertambahnya pori yang terbuka maka nilai konduktivitas akan bertambah. Dengan bertambahnya nilai konduktivitas maka akan menambah daya serap radiasi gelombang elektromagnetik[18].

\section{Hasil Pengujian XRD Raw Material}

Pengujian XRD digunakan mengetahui adanya perubahan struktur mikro yang terjadi pada biokarbon eceng gondok selama proses karbonisasi. Hasil XRD pada pada Tabel 1 menunjukkan bahwa pada temperatur $500^{\circ} \mathrm{C}$ sudah mulai terbentuk kristal karbon sebanyak $8 \%$ pada sudut $26,3472^{\circ}$ dengan bentuk kristal rhombohedral. Dengan kenaikan temperatur maka prosentase kristal

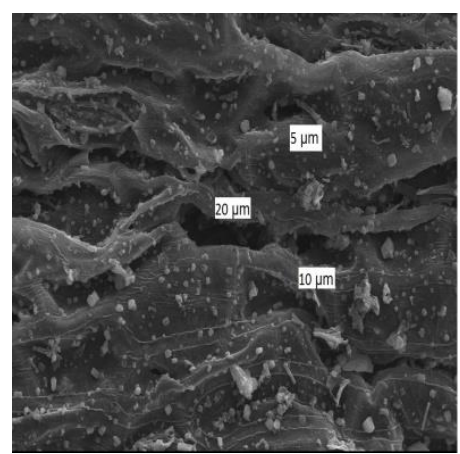

a

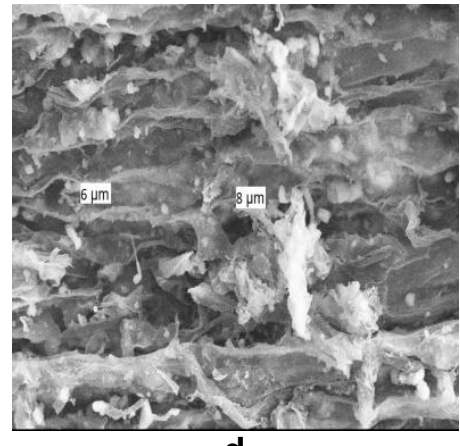

d

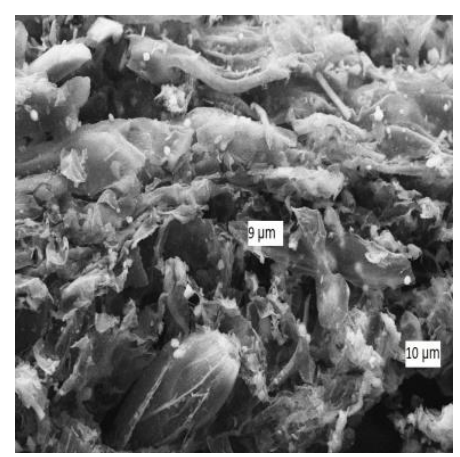

b

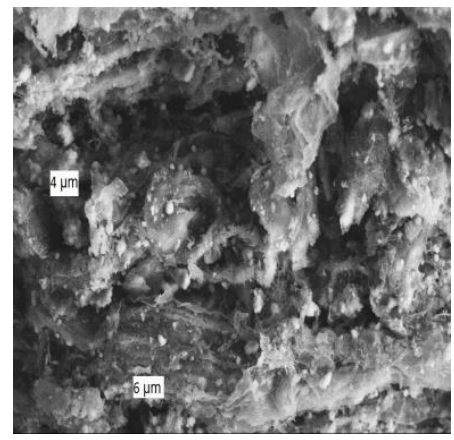

\section{(1)}

karbon bertambah naik, dengan nilai mencapai $14 \%$ pada temperatur $900^{\circ} \mathrm{C}$ dan $1000^{\circ} \mathrm{C}$.

Gambar 5 menunjukkan posisi-posisi sudut $2 \Theta$ yang terdapat kristal karbon dengan kode 01-075-0444, dimana pada posisi sudut $26,310^{\circ}$ memiliki intensitas $100 \%$, yang berarti bahwa kristal karbon terbentuk pada sudut tersebut. Berdasarkan hal tersebut maka kristal karbon yang terbentuk di dalam biokarbon eceng gondok berbentuk seperti grafit, dimana grafit berada pada posisi sudut 26,70[13]. Dengan semakin banyak kristal karbon yang tumbuh dalam biokarbon eceng gondok maka akan semakin menaikkan nilai kondutivitas listriknya, dengan semakin banyak konduktivitas listriknya maka akan menambah kemampuan biokarbon eceng gondok untuk menyerap radiasi gelomban elektromagnetik. Disamping itu, di dalam biokarbon eceng gondok juga terdapat struktur yang berbentuk amorf, seperti yang ditunjukkan dalam hasil XRD biokarbon eceng gondok Gambar 6 . Sehingga stuktur biokarbon eceng gondok berbentuk kristal dan amorf.

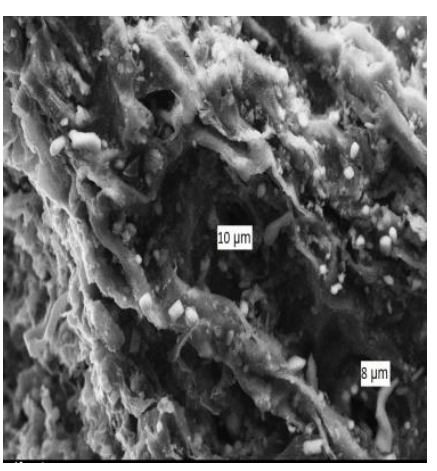

C

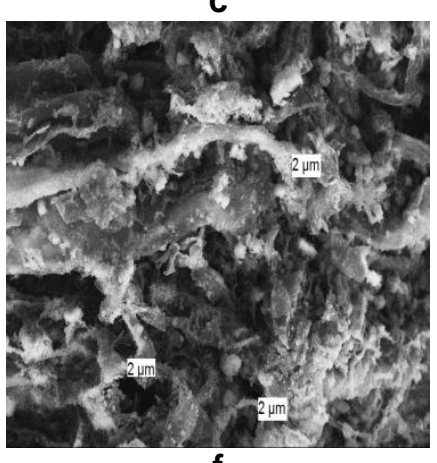

f

Gambar 3. Hasil Pengujian SEM Hasil biokarbon eceng gondok temperatur karbonisasi (a) $500^{\circ} \mathrm{C},\left(\right.$ b) $600^{\circ} \mathrm{C}$, (c) $700^{\circ} \mathrm{C}$, (d) $800^{\circ} \mathrm{C},(e) 900^{\circ} \mathrm{C}$, dan (f) $1000^{\circ} \mathrm{C}$ dengan pembesaran $2000 \mathrm{x}$ 


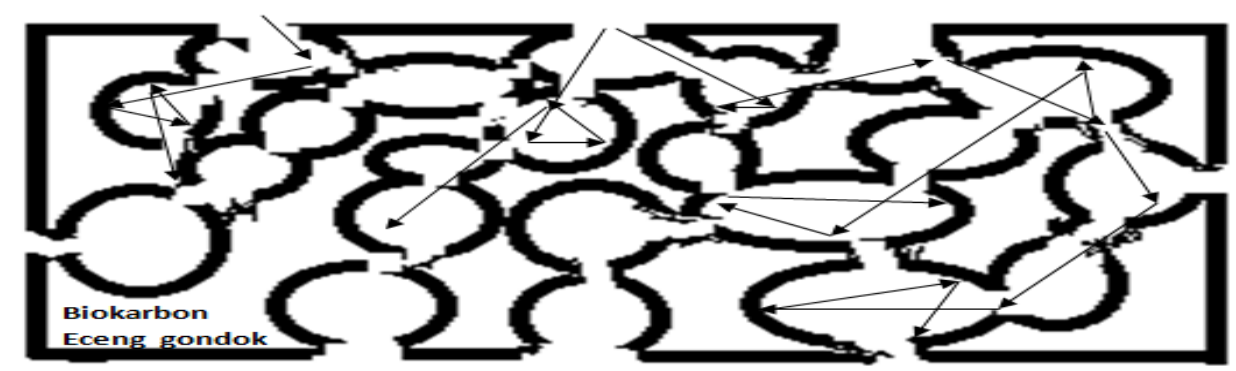

Gambar 4. Skema llustrasi Penyerapan Radiasi Gelombang Elektromagnetik oleh Biokarbon Eceng Gondok

Tabel 1. Hasil XRD Prosentase Kristal Karbon Pada Biokarbon Eceng Gondok

\begin{tabular}{cccc}
\hline No & Temperatur $\left({ }^{\circ} \mathrm{C}\right)$ & Posisi Sudut $2 \Theta\left({ }^{\circ}\right)$ & Prosentase $(\%)$ \\
\hline 1 & 500 & 26,3472 & 8 \\
2 & 600 & 26,2900 & 9 \\
3 & 700 & 26.2700 & 10 \\
4 & 800 & 26.2224 & 11 \\
5 & 900 & 26.3939 & 14 \\
6 & 1000 & 26.2618 & 14 \\
\hline
\end{tabular}

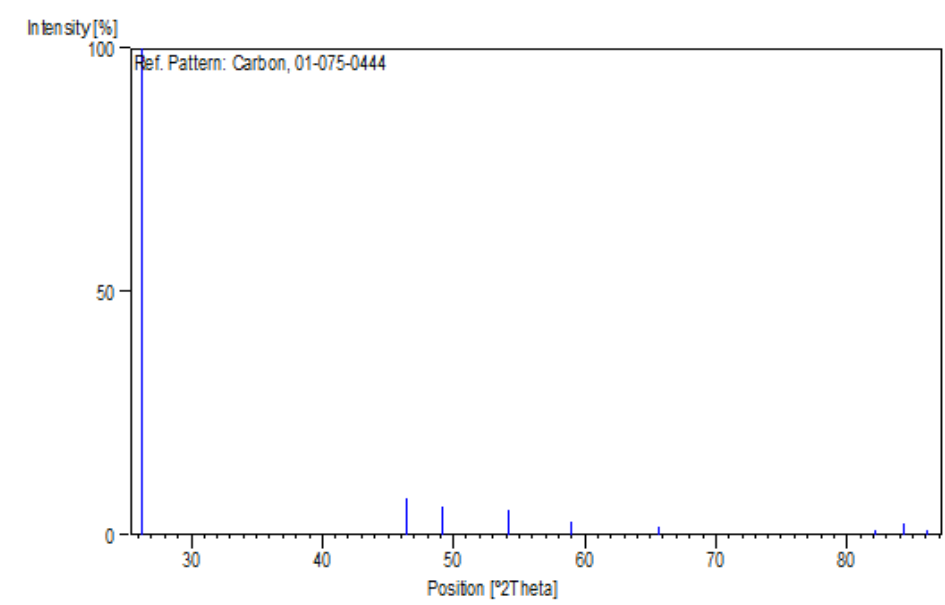

Gambar 5. Hasil XRD Posisi Krital Karbon Dengan Kode 01-072-154044 Pada Biokarbon Eceng Gondok

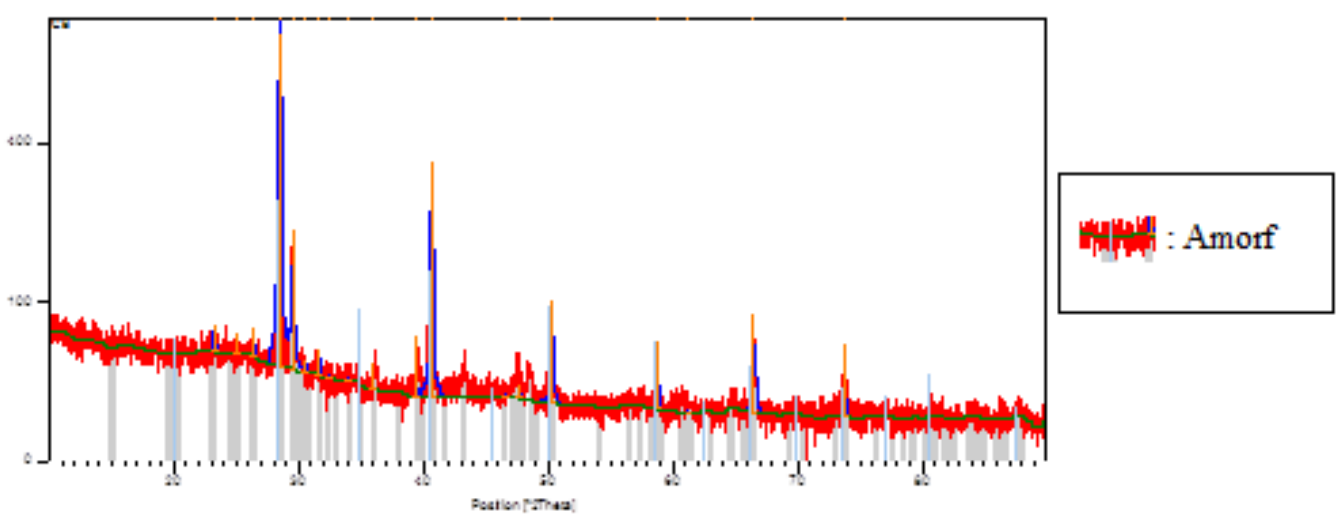

Gambar 6. Hasil XRD dari Biokarbon Eceng Gondok pada temperatur $500^{\circ} \mathrm{C}$ 


\section{KESIMPULAN}

Berdasarkan penelitian yang telah dilakukan didapatkan kesimpulan sebagai berikut:

1. Semakin tinggi temperatur karbonisasi maka semakin banyak pori-pori dari biokarbon eceng gondok yang terbuka, dengan diameter $2 \mu \mathrm{m}$ pada temperatur $1000^{\circ} \mathrm{C}$

2. Struktur biokarbon eceng gondok berbentuk kristal dan amorf

3. Semakin tinggi temperatur karbonisasi maka semakin tinggi prosentase terbentuknya kristal karbon dalam biokarbon eceng gondok dengan nilai 14 $\%$ pada temperatur $900^{\circ} \mathrm{C}$ dan $1000^{\circ} \mathrm{C}$

4. Biokarbon eceng gondok merupakan bahan yang cocok digunakan untuk RAM

\section{UCAPAN TERIMA KASIH}

Terima kasih disampaikan kepada Direktorat Riset dan Pengabdian Masyarakat (DRPM) Direktorat Jenderal Penguatan Riset dan Pengembangan Kementerian Riset, Teknologi, dan Pendidikan Tinggi yang telah memberi dukungan dana terhadap penelitian ini.

\section{DAFTAR PUSTAKA}

[1] Thomassin, J. M., Jerome, C., Pardoen, T., Bailly, C., Huynen, I., \& Detrembleur, C. (2013). Polymer/carbon based composites as electromagnetic interference (EMI) shielding materials. Materials Science and Engineering R: Reports, 74(7), 211-232.

[2] Liu, S., Chen, X., Zhang, A., Yan, K., \& Ye, Y. (2014). Electromagnetic Performance of Rice Husk Ash. BioResources, 9, 23282340.

[3] Wu, K. H., Ting, T. H., Liu, C. I., Yang, C. C., \& Hsu, J. S. (2008). Electromagnetic and microwave absorbing properties of $\mathrm{Ni0.5Zn0.5Fe2O4/bamboo} \mathrm{charcoal} \mathrm{core-}$ shell nanocomposites. Composites Science and Technology, 68(1), 132-139

[4] Suliyanti, M. M., Yudasari, N., Indayaningsih, N., Tresna, W. P., Wahyu, Y., \& Hercuadi, A. Y. (2012). Pembuatan rf absorber berbasis karbon lokal untuk aplikasi radar. InSinas, 137-140

[5] Liu, Q., Gu, J., Zhang, W., Miyamoto, Y., Chen, Z., \& Zhang, D. (2012). Biomorphic porous graphitic carbon for electromagnetic interference shielding. $J$.
Mater. Chem., 22(39), 21183-21188.

[6] Velev, P. N., Nenkova, S. K., \& Kulevski, M. N. (2012). Polymer composites on the basis of lignocellulose containing copper sulfide for electromagnetic wave protection. Bulgarian Chemical Communications, 44(2), 164-171.

[7] Ratnani, R. D. (2005). Proses Pirolisis Eceng Gondok (Eichhornia Crassipes) Menjadi Karbon Aktif Dengan Bahan Pengaktif Natrium Klorida ( $\mathrm{NaCl})$. Momentum, 1(1), 5-10.

[8] Salamah, S. (2008). Pembuatan Karbon Aktif Dari Kulit Buah Mahoni Dengan Perlakuan Perendaman Larutan Koh. Prosiding Seminar Nasional Teknoin2, (5), 55-59.

[9] Suhartana. (2006). Pemanfaatan Baku Arang Aktif Dan Aplikasinya Untuk Penjernihan Air Sumur Di Desa Belor. Berkala Fisika, 9(3), 151-156.

[10] Haniffudin, N., \& Diah, S. (2013). Pengaruh Variasi Temperatur Karbonisasi dan Karbon Aktif Tempurung Kelapa dan Kapasitansi Electric Double Layer Capacitor (EDLC). Jurnal Teknik Pomits, 2(1), F-13-F-17.

[11] Hao, W. (2014). Refining of hydrochars/ hydrothermally carbonized biomass into activated carbons and their applications. Stockholm University.

[12] Basu, P. (2010). Biomass Gasification and Pyrolysis Practical Design and Theory. Oxford: Elsevier Inc.

[13] Pari, G. (2011). Pengaruh Selulosa Terhadap Strukturkarbon Arang Bagian I: Pengaruh Suhu Karbonisasi. Jurnal Penelitian Hasil Hutan, 29(1), 33-45.

[14] Kartika, V., Ratnawulan, \& Gusnedi. (2016). Pengaruh Variasi Suhu Karbonisasi Terhadap Mikrostruktur Dan Derajat Kristalinitas Karbon Aktif Kulit Singkong Sebagai Bahan Dasar Gdl (Gas Diffussion Layer). Pillar Of Physics, 7(April), 105-112. 
[15] Nasution, Z. A., \& Rambe, S. M. (2011). Pengaruh Temperatur Karbonisasi Terhadap Pembentukan Struktur Pori Pada Arang Cangkang Sawit. Jurnal Dinamika Penelitian Industri, 22(2), 100105.

[16] S, F. R. . T. ., Handoko, E., Soegijono, B., Umiyatin, Linah, \& Agustriany, R. (2008). Pengaruh Temperatur Terhadap Pembentukan Pori Pada Arang Bambu. In Prosiding Seminar Nasional Sain dan Teknologi - II (p. V-240-V-245).

[17] Destyorini, F., Suhandi, A., Subhan, A., \& Indayaningsih, N. (2010). Pengaruh Suhu Karbonisasi Terhadap Struktur Dan Konduktivitas Listrik Arang Serabut

Kelapa. Jurnal Fisika, 10(2), 122-132.

[18] Chung, D. D. L. (2001). Electromagnetic interference shielding effectiveness of carbon materials. Carbon, 39, 279-285. 